\title{
ALAT PENGUKUR GETARAN, SUARA DAN SUHU MOTOR INDUKSI TIGA FASA SEBAGAI INDIKASI KERUSAKAN MOTOR INDUKSI BERBASIS ARDUINO
}

\author{
${ }^{1}$ Deffi Meidiasha, ${ }^{2}$ Muhammad Rif'an, ${ }^{3}$ Massus Subekti. \\ ${ }^{1,2,3}$ Pendidikan Teknik Elektro, Fakultas Teknik, Universitas Negeri Jakarta \\ 1,2,3 Email: meidiashadeffi@gmail.com ; m.rifan@yahoo.co.id ; masus@unj.ac.id
}

\begin{abstract}
The purpose of this research is to design, to build, and to test vibration, sound and temperature control devices on Motor on 3-phases motor for damage to a arduino based 3-phase induction motor. The research is conducted in the Motor Installation Lab. 1st floor Faculty of Engineering, State University of Jakarta. At June 2019 until December 2019.This research uses engineering methods. The research subjects used are AC motors. Data analysis technique used is descriptive analysis with data collection techniques namely laboratory observation using testing instruments. The results showed that the device can measure the level of vibration and sound (noise) of the motor through the LOW and HIGH conditions of the vibration sensor and sound sensor, while the device can measure the level of the motor temperature through data from the LM35 temperature sensor. So it can be concluded that the vibration, sound and temperature gauges can function well in motor damage indications.
\end{abstract}

Keywords: Induction motor, Vibration Sensor, Sound Sensor, Temperature Sensor

\begin{abstract}
Abstrak
Penelitian ini bertujuan untuk mendesain dan membuat alat pengatur getaran, suara dan suhu motor induksi 3-phasa sebagai indikasi kerusakan pada motor induksi 3-phasa berbasis arduino. Penelitian dilaksanakan di Laboratorium Instalasi Motor Fakultas Teknik Universitas Negeri Jakarta. Pada Bulan Juni 2019 sampai Desember 2019.Penelitian ini menggunakan metode rekayasa teknik. Subyek penelitian yang digunakan yaitu motor AC induksi 3-phasa. Teknik analisis data yang digunakan yaitu analisis deskriptif dengan teknik pengumpulan data yaitu observasi laboratorium menggunakan instrumen pengujian.Hasil penelitian menunjukkan bahwa alat dapat mengukur tingkat getaran dan suara (noise) motor melalui kondisi $L O W$ dan $H I G H$ dari sensor getaran dan sensor suara, sedangkan alat dapat mengukur tingkat suhu motor melalui data dari sensor suhu LM35. Sehingga dapat disimpulkan bahwa alat pengukur getaran, suara dan suhu dapat berfungsi dengan baik dalam mengindikasi kerusakan motor.
\end{abstract}

Kata kunci: Motor Induksi, Sensor Getar, Sensor Suara, Sensor Suhu

\section{PENDAHULUAN}

Motor induksi (MI) merupakan alat listrik yang mengubah energi listrik menjadi energi mekanik yang berupa tenaga putar. Motor induksi banyak dipakai sebagai penggerak untuk mengerjakan banyak proses di industri seperti menggerakkan blower (penghasil angin) berkapasitas besar yang dipakai untuk pembakaran di dalam tungku peleburan, menggerakkan conveyor (pengangkut bahan), menggerakkan pompa air untuk sirkulasi air pendingin dan lain - lain. Meskipun MI cukup handal tetapi pada kenyataannya dapat saja mengalami banyak masalah pada saat beroperasi yang menyebabkan kerusakan total pada motor induksi tersebut.

Pada umumnya motor induksi kuat dan handal. Tetapi, lingkungan kerja, instalasi dan faktor produksi bisa menyebabkan kerusakan pada rotor dan stator. Kerusakan tersebut tidak hanya menurunkan efisiensi kerja dari mesin, melainkan bisa menimbulkan pengaruh bahaya untuk produksi yang berkelanjutan dan keamanannya. Ada beberapa yang dapat mempengaruhi kerusakan motor yaitu tegangan, arus, frekuensi, keseimbangan kekebalan tegangan, temperatur, getaran, kebisingan (noise).

Motor induksi yang digunakan secara terus menerus akan mengalami proses penuaan motor secara alami yang dapat menyebabkan kekusakan pada motor induksi. Apabila kerusakan pada motor induksi tidak dapat dideteksi sedini mungkin akan dapat mengakitkan kerusakan yang sangat parah dengan berbagai tipe kerusakan. Kerusakan motor akan menyebabkan hilangnya waktu produktif akibat perbaikan mesin yang cukup lama, pemeliharaan biaya yang sangat besar, akibat banyaknya komponen yang harus diganti. Kerusakan total motor induksi pada saat berlangsungnya proses produksi dapat mengakibatkan rendahnya mutu barang jadi yang dihasilkan hingga sampai berhentinya proses produksi itu sendiri. Salah satu contoh kerusakan motor induksi adalah Stress mekanik akibat pola operasi. Stress mekanik terjadi akibat kelebihan beban dan perubahan beban secara tiba - tiba yang dapat mengakibatkan kerusakan bearing dan 
patahnya rotor bar. ${ }^{[1]}$ Menurut survei dari Electric Power Research Institute (EPRI) yang mensurvei 6312 motor dan survei dari Motor Reliability Working Group (IEEE-IAS) yang mensurvei 1141 motor $^{[2]}$. Indikasi adalah hasil dari kegiatan siap siaga dengan apa yang terjadi pada suatu keadaan tertentu dan merupakan input bagi proses perencanaan dan pengambilan keputusan ${ }^{[3]}$.

Tujuan dari mengindikasi adalah memecahkan suatu masalah dengan mengumpulkan petunjuk dengan berbagai cara tergantung metode yang diterapkan ${ }^{[4]}$.

Jadi inilah yang menjadi alasan utama mengapa peneliti mencoba menggunakan mengembangkan perangkat yang mampu mengindikasikan kondisi kerusakan motor melalui pendekatan noise monitoring (monitoring suara), vibration monitoring (monitoring getaran), dan temperature monitoring (monitoring suhu).

\section{METODE PENELITIAN Metode dan Perancangan Penelitian}

Metode penelitian yang digunakan yaitu menggunakan metode rekayasa teknik. Metode penelitian ini merupakan yang digunakan untuk menghasilkan produk tertentu, dan menguji keefektifan produk tersebut.

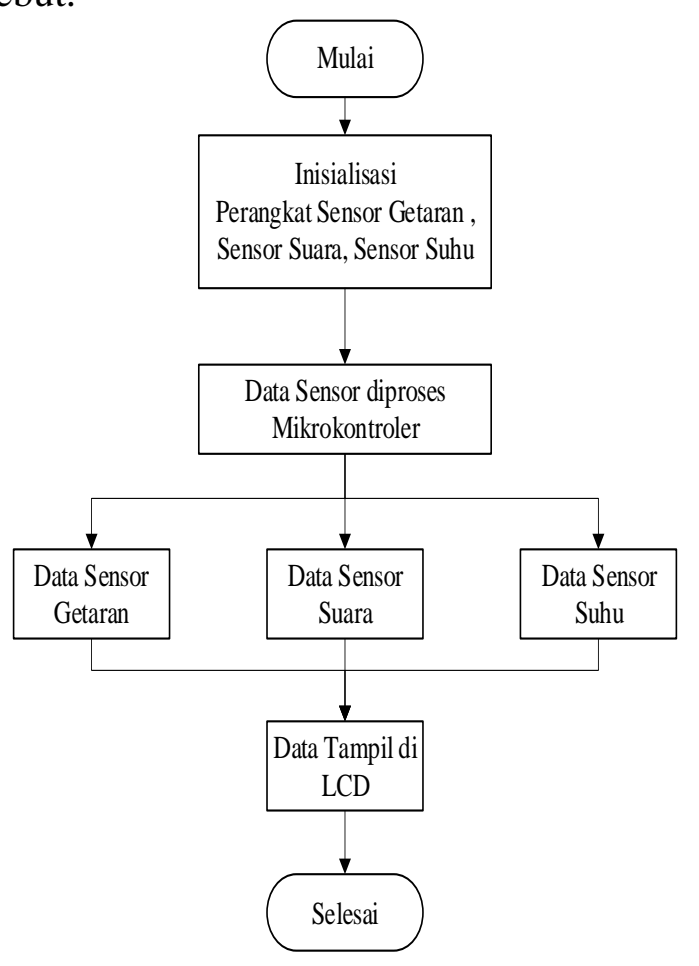

Gambar 1. Flowchart Penelitian

Teknik pengumpulan data yang digunakan dalam penelitian ini adalah metode observasi meliputi pencarian sumber literature. Adapun data - data yang digunakan dalam menyusun skripsi ini, yaitu berupa data primer dan sekunder. Data sekunder yaitu sumber data yang tidak langsung memberikan data kepada pengumpul data, misalnya lewat orang lain atau lewat dokumen ${ }^{[5]}$.

\section{Teknik Analisis Data}

Teknik analisis data adalah kegiatan mengubah hasil penelitian menjadi informasi yang dapat digunakan untuk mengambil sebuah kesimpulan dalam suatu penelitian. Tahap pertama merancang alat sesuai dengan jenis perlengkapan yang dipilih.

Kemudian diikuti dengan perancangan program menggunakan perangkat lunak Arduino IDE Versi 1.8.9 Tahap berikutnya adalah melakukan perakitan alat untuk memprediksi kerusakan motor induksi tiga fasa, dan pengunduhan program ke dalam Arduino Uno sebagai mikrokontroller.

\section{HASIL PENELITIAN}

Pada tahap perancangan mikrokontroller dibutuhkan komponen - komponen pendukung lainnya, sehingga Arduino Uno dapat bekerja dengan baik. Berikut ini merupakan gambar board mikrokontroller Arduino Uno.

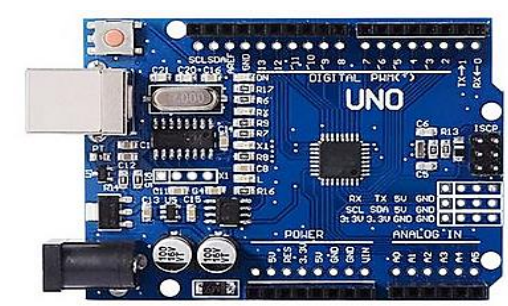

Gambar 2. Arduino Uno

\section{Sensor Shock SW-420}

Sensor shock merupakan salah satu sensor yang dapat mendeteksi getaran yang nantinya akan diproses untuk kepentingan percobaan ${ }^{[6]}$.

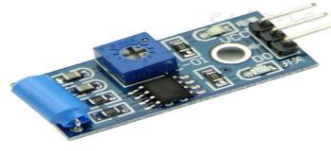

Gambar 3. Sensor Shock SW-420 


\section{Sensor Suara Sound Microphone KY-037}

Sound Microphone Sensor Detection Module merupakan module sensor yang mensensing besaran suara untuk diubah menjadi besaran listrik yang akan diperoleh mikrokontroller $^{[7]}$.

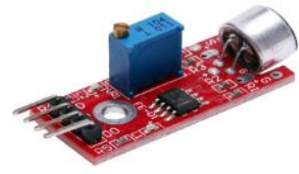

Gambar 4. Sensor Suara KY-037

\section{Sensor Suhu LM35}

Sensor IC LM 35 merupakan chip IC produksi National Semiconductor yang berfungsi untuk mengetahui temperature suatu objek atau ruangan dalam bentuk besaran elektrik, atau dapat juga di definisikan sebagai komponen elektronika yang berfungsi untuk mengubah perubahan temperature yang diterima dalam perubahan besar elektrik ${ }^{[8]}$.

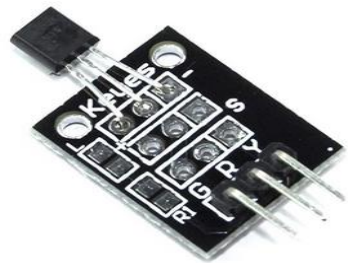

Gambar 5. Sensor Suhu LM35

\section{Rangkaian Sensor Pada Motor}

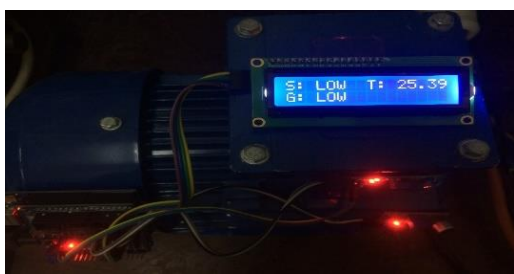

\section{Hasil Penelitian}

Deskripsi hasil penelitian merupakan gambaran dari data hasil penelitian yang telah dilaksanakan. Di bawah ini akan dijelaskan deskripsi data dari penelitian di Rumpun Teknik Elektro Fakultas Teknik Universitas Negeri Jakarta. Hasil penelitian alat pengukur getaran, suara dan suhu motor induksi tiga fasa untuk memprediksi indikasi kerusakan motor induksi terdiri dari data pengujian perangkat sensor yang digunakan.

\begin{tabular}{ccc} 
No. & Perangkat & Tegangan \\
\hline 1. & Arduino Uno & 4.9 Volt \\
2. & Sensor getaran & 4.95 Volt \\
3. & Sensor suhu & 4.8 Volt \\
4. & Sensor suara & 4.8 Volt \\
5. & Display LCD & 4.7 Volt
\end{tabular}

Tabel 1. Pengujian Tegangan

\begin{tabular}{ccc}
$\begin{array}{c}\text { Pengujian } \\
\text { Sensor } \\
\text { Getaran }\end{array}$ & $\begin{array}{c}\text { Kondisi } \\
\text { Motor } \\
\text { Baik }\end{array}$ & $\begin{array}{c}\text { Kondisi } \\
\text { Motor } \\
\text { Buruk }\end{array}$ \\
\hline 1. & LOW & HIGH \\
2. & LOW & HIGH \\
3. & LOW & HIGH \\
4. & LOW & HIGH \\
5. & LOW & HIGH
\end{tabular}

Tabel 2. Pengujian Sensor Getaran

\begin{tabular}{ccc}
$\begin{array}{c}\text { Pengujian } \\
\text { Sensor } \\
\text { Suara }\end{array}$ & $\begin{array}{c}\text { Kondisi } \\
\text { Motor } \\
\text { Baik }\end{array}$ & $\begin{array}{c}\text { Kondisi } \\
\text { Motor } \\
\text { Buruk }\end{array}$ \\
\hline 1. & LOW & HIGH \\
2. & LOW & HIGH \\
3. & LOW & HIGH \\
4. & LOW & HIGH \\
5. & LOW & HIGH
\end{tabular}

Tabel 3. Pengujian Sensor Suara

$\begin{array}{ccc}\text { No. } & \begin{array}{c}\text { Kondisi } \\ \text { Motor }\end{array} & \begin{array}{c}\text { Output } \\ \text { Sensor } \\ \text { Suhu }\end{array}\end{array}$

\begin{tabular}{cccc}
\hline 1 & Baik & $75^{\circ} \mathrm{c}$ & Sedang \\
2 & Rusak & $88^{\circ} \mathrm{c}$ & Buruk \\
3 & Baik & $70^{\circ} \mathrm{c}$ & Sedang \\
4 & Rusak & $89^{\circ} \mathrm{c}$ & Buruk \\
5 & Baik & $67^{\circ} \mathrm{c}$ & Sedang \\
6 & Rusak & $92^{\circ} \mathrm{c}$ & Buruk \\
7 & Baik & $75^{\circ} \mathrm{c}$ & Sedang \\
8 & Rusak & $85^{\circ} \mathrm{c}$ & Buruk \\
9 & Baik & $72^{\circ} \mathrm{c}$ & Sedang \\
10 & Rusak & $88^{\circ} \mathrm{c}$ & Buruk \\
\hline
\end{tabular}


Tabel 4. Hasil Pengujian Sensor Suhu

\begin{tabular}{cccc} 
Getaran & Suara & Suhu & $\begin{array}{c}\text { Kondisi } \\
\text { Motor }\end{array}$ \\
\hline HIGH & HIGH & $88^{\circ} \mathrm{c}$ & Rusak \\
HIGH & HIGH & $85^{\circ} \mathrm{c}$ & Rusak \\
HIGH & HIGH & $87^{\circ} \mathrm{c}$ & Rusak \\
HIGH & HIGH & $63^{\circ} \mathrm{c}$ & Rusak \\
HIGH & HIGH & $68^{\circ} \mathrm{c}$ & Rusak \\
HIGH & HIGH & $75^{\circ} \mathrm{c}$ & Rusak \\
LOW & HIGH & $65^{\circ} \mathrm{c}$ & Rusak \\
LOW & HIGH & $73^{\circ} \mathrm{c}$ & Rusak \\
LOW & HIGH & $78^{\circ} \mathrm{c}$ & Rusak \\
LOW & LOW & $63^{\circ} \mathrm{c}$ & Ideal \\
LOW & LOW & $66^{\circ} \mathrm{c}$ & Ideal \\
LOW & LOW & $66^{\circ} \mathrm{c}$ & Ideal \\
\hline
\end{tabular}

Tabel 5. Pengujian Keseluruhan Sensor

\begin{tabular}{|c|c|c|}
\hline No & Komponen & Hasil \\
\hline 1 & Mikrokontroller & $\begin{array}{c}\text { Dapat memproses } \\
\text { keseluruhan data dari sensor } \\
\text { dan mengirimkan data ke } \\
\text { mikrokontroller. }\end{array}$ \\
\hline 2 & Sensor Getaran & $\begin{array}{l}\text { Mampu mengidentifikasi } \\
\text { batas getaran sesuai dengan } \\
\text { batas kalibrasi dengan baik. } \\
\text { Mampu mengidentifikasi }\end{array}$ \\
\hline 3 & Sensor Suara & $\begin{array}{c}\text { batas suara atau noise sesuai } \\
\text { dengan batas kalibrasi } \\
\text { dengan baik. }\end{array}$ \\
\hline 4 & Sensor Suhu & $\begin{array}{c}\text { Mampu mengidentifikasi } \\
\text { batas temperature sesuai } \\
\text { dengan batas kalibrasi }\end{array}$ \\
\hline 5 & LCD & $\begin{array}{l}\text { temperature dengan baik. } \\
\text { Mampu menampilkan data } \\
\text { pengukuran sensor dengan } \\
\text { baik sesuai dengan baris } \\
\text { kode program. }\end{array}$ \\
\hline
\end{tabular}

Tabel 5. Pengujian Keseluruhan Sensor

\section{Pembahasan}

Berdasarkan hasil yang telah didapat, peneliti akan menganalisis hasil pengujian perangkat yang digunakan pada unjuk kerja alat secara keseluruhan sesuai dengan data pengujian sebelumnya

\section{Pembahasan Pengujian Tegangan}

Pengujian tegangan mendapatkan hasil bahwa alat secara keseluruhan mendapatkan cukup catu daya untuk beroperasi dengan baik. Tegangan catu daya berada pada batas kerja ideal pada rentang 4,8-5 Volt.

\section{Pembahasan Pengujian Sensor Getaran}

Pengujian sensor getaran dalam mengidentifikasi kerusakan motor pada pengujian keseluruhan sensor didapatkan hasil bahwa sensor getaran dapat merespon getaran berlebih yang dihasilkan oleh sampel motor yang dalam kondisi buruk dengan baik, hal ini dipengaruhi oleh tingkat kalibrasi yang dilakukan sebelumnya untuk mengkonfigurasi kapan sensor getar merespon getaran pada batas yang diinginkan untuk sampai berlogika HIGH.

\section{Pembahasan Pengujian Sensor Suara}

Pengujian sensor suara dalam mengidentifikasi kerusakan motor pada pengujian keseluruhan sensor didapatkan hasil bahwa sensor suara dapat merespon suara atau noise yang dihasilkan oleh sampel motor yang kurang baik, hal ini juga dipengaruhi oleh perlakuan kalibrasi sensor sebelumnya dalam mengatur tingkat sensitifitas gangguan suara atau noise dari motor.

\section{Pembahasan Pengujian Sensor Suhu}

Pengujian sensor suhu dalam mengidentifikasi kerusakan motor pada pengujian keseluruhan sensor didapatkan hasil bahwa sensor suhu mampu mengukur suhu atau temperature dari body motor yang dihasilkan dari sampel motor dengan kondisi buruk, data yang dihasilkan sesuai dengan acuan kondisi motor pada nameplate motor.

\section{Pembahasan Pengujian Keseluruhan Sensor}

Pengujian keseluruhan sensor mendapatkan data bahwa alat mampu mengidentifikasi indikasi kondisi motor dalam kondisi yang baik atau buruk, hal ini dikarenakan motor yang dalam kondisi buruk memiliki getaran yang berlebih, suara noise yang berisik dan suhu body motor menjadi cepat panas, hal ini dapat dijadikan acuan oleh alat sebagai monitoring indikasi kerusakan motor yang sedang digunakan.

\section{KESIMPULAN}

Monitoring indikasi kerusakan motor ini setelah dilakukan tahap pengujian dari perangkat yang ada maka dapat disimpulkan bahwa sensor getaran dapat dengan baik memonitoring kondisi motor sebagai identifikasi indikasi kerusakan 
pada motor dengan baik, hal ini ditunjukkan pada tahap pengujian sensor keseluruhan.

Pada alat dalam menguji sampel uji motor mampu mengidentifikasi indikasi motor yang masih dalam kondisi baik dan mengidentifikasi indikasi motor yang sudah dalam kondisi buruk.

Pada pengujian sensor suhu didapatkan nilai yang stabil yaitu dalam kondisi normal pada angka $75^{\circ} \mathrm{c}$

Semakin besar suara yang dihasilkan oleh motor induksi maka akan semakin panas kondisi motor induksi dan akan terjadi indikasi rusak dengan output pada sensor yaitu HIGH sedangkan kondisi motor yang baik hasil adalah LOW.

Penggunaan sensor dapat dikembangkan menggunakan sensor dengan tipe data analog sehingga dapat dipantau data berupa angka. Penggunaan sensor dapat dipilih yang tidak rentan gangguan misalnya sensor suara yang memiliki kepekaan suara yang baik dan tidak mudah terganggu oleh suara atau noise dari lingkungan sekitar.

\section{DAFTAR PUSTAKA}

[1] Yudiastawan, 2009. Pengukuran Sudut Menggunakan Sensor Dengan Basis Mikrokontroller. Yogyakarta: Universitas Sanata Dharma.

[2] Da Silva, Albert. Induction Motor Fault Diagnostic and Monitoring Method, Marquette University, Milwaukee, Mei 2006.

[3] Shahani, Mala. 2010. Indikasi Kerusakan. Yogyakarta: C. V Andi Offset.

[4] Mauludin, Mochammad Aldi. 2017. Prototipe

Sistem Pengukur Kadar Gas Carbon Monoxide (Co) Pada Kabin Mobil Berbasis Sensor Mq-7 dan Arduino Uno [skripsi]. Jakarta: Fakultas Teknik Universitas Negeri Jakarta.

[5] Sugiyono. 2013. Metode Penelitian Kuantitatif,

Kualitatif dan R\&D. Bandung: Alfabeta.

[6] Pillay, Xu. 1996. Motor Current Signature Analysis. Georgia: IDM Controls.

[7] Djokosetyadjo, M.J. 1932. Motor Induksi. Jakarta:

Bhratara Karya Aksara.

[8] Hariyanto. "Pengembangan Sensor Getar ADXL335 Sebagai Petunjuk Perawatan Mesin Bubut Horizontal." jurnal umj, 2015. 